\title{
Um projeto sobre Florações de algas nocivas (FANs) na Baía de Sepetiba discute o território pesqueiro
}

A Project about HABs (harmful algal bloom) in the Sepetiba Bay discusses the fishing territory

\section{Introdução}

A cidade do Rio de Janeiro sediou a Conferência das Nações Unidas sobre Desenvolvimento Sustentável, a aguardada Rio+20, evento global promovido vinte anos depois da Conferência das Nações Unidas sobre Meio Ambiente (Rio 92) de 13 a 22 de junho de 2012. A reunião sobre meio ambiente contou com representantes dos 193 Estados-membros da ONU e a presença de milhares de participantes dos mais variados setores da sociedade civil e terminou sem maiores avanços, considerando a grande expectativa em torno do encontro e das diversas e cada vez, mais graves problemáticas socioambientais. Questões relacionadas aos oceanos, às águas continentais, ao clima e emissões de carbono, reservas naturais, biodiversidade, atividades agrícolas e uso de solo, dentre outras, ao final tiveram mais espaço nas discussões que se deram junto às instâncias de poder local, como no Fórum "Cidades Sustentáveis e Inovação", por exemplo. Se ainda havia dúvidas, o saldo positivo de tais encontros confirmaram que ações locais, como a de grupos articulados ou setores e temas focais, são estratégias de grande eficácia ou validade para participação em lutas pelo meio ambiente ou quaisquer questões visando ampliar o controle social nas esferas de decisão.

Os movimentos sociais articularam várias ações e protestos, sem os quais a reunião teria sido uma exposição de "problemas já resolvidos com suas soluções já alcançadas". Uma dessas ações concretizou-se em junho de 2012 por uma visita a algumas das áreas mais afetadas pelo atual modelo de crescimento econômico em curso no estado do Rio de Janeiro que privilegia atividades altamente impactantes, em especial, a petroquímica, a siderurgia e a infraestrutura portuária para escoamento da produção mineral. As visitas foram chamadas

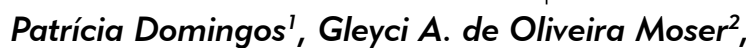
Marcelo Manzi Marinho ${ }^{3}$, Igor Tavares Sampaio ${ }^{4}$, Gisele Costa ${ }^{5}$, Henrique Tolentino ${ }^{6}$ e Renan Silva Arruda $^{7}$

\section{Resumo}

Este relato descreve um projeto de extensão sobre os riscos de florações de algas nocivas (FANs) e os atuais impactos socioambientais sobre o território pesqueiro da Baía de Sepetiba, em início de execução por iniciativa do IBRAG, FAOC, NIESBEF/ UERJ e GEPEADS/UFRRJ. Os objetivos principais são: (I) contribuir para a discussão e conhecimento do problema por professores e alunos de 40 escolas públicas do entorno da baía; (II) monitorar a ocorrência de FANs; (III) mapear a percepção de pescadores sobre seu território de pesca. A região da Baía de Sepetiba foi escolhida para a implantação de megaempreendimentos industriais e novos terminais portuários que criam zonas de exclusão de pesca. Ao mesmo tempo, registros anteriores de FANs na baía e o risco de novas florações, representam potencial redução ao território de pesca, com prejuízos para o ecossistema e para o ser humano. É fundamental a divulgação de causas e efeitos de FANs, colaborando para a construção coletiva de atitudes que minimizem seus riscos para saúde pública. São realizadas amostragens mensais da água para o monitoramento de FANs, desde FEV/2013. Entrevistas com os pescadores, a cada saída, associado aos resultados das análises de água subsidiarão a produção de um material didático para as escolas.

Palavras-chave: Baía de Sepetiba; Florações de Algas Nocivas; Território Pesqueiro.

Área Temática: Meio Ambiente Linha de Extensão: Questões Ambientais

\footnotetext{
' Docente UERJ. E-mail: patdomingos@uerj.br

2 Docente UERJ. E-mail: gleyci_moser@uerj.br

3 Docente UERJ. E-mail: manzi@uerj.br

${ }^{4}$ Aluno de graduação. E-mail: igor_tavares10@yahoo.com.br

${ }^{5}$ Aluno de graduação. UNIGRANRIO. E-mail: giselle_costa@live.com

${ }^{6}$ Aluno de graduação. UERJ. E-mail: henriquetmm@gmail.com

${ }^{7}$ Aluno degraduação.UNIGRANRIO.E-mail:renan.arruda@ymail.com
} 
de "Toxic Tour" (TOXIC TOURS: Missões de intercâmbio e mobilização: Conhecendo o "Lado B" do Rio de Janeiro) e mobilizaram os representantes das chamadas "mídias livres" de várias partes do mundo. Este evento teve três frentes, com a realização do "tour" em locais que ficaram "escondidos" da reunião principal, como, Baía de Sepetiba, Baía de Guanabara e Magé. Em comum destacavam-se megaempreendimentos poluentes que vêm afetando populações de baixa renda da região do Grande Rio. Participamos da visitação à Baía de Sepetiba num dos barcos escalados para o evento. Durante a excursão, lideranças de pescadores da região relataram suas percepções e experiências para os visitantes de cada barco. O produto dessas ações foi exibido em sessão pública no Cine Joia, em agosto de $2012^{1}$ dando divulgação a esses fatos.

Este encontro despertou nosso interesse para a questão da prática da pesca artesanal e de como o grupo de pescadores têm tido suas atividades desconsideradas e limitadas pelas opções desenvolvimentistas em curso no estado e nos remeteu à realização de uma oficina para pescadores da Baía de Sepetiba, durante a Rio +20 , integrando a Cúpula dos Povos.

A oficina visou divulgar os efeitos da ocorrência de florações de algas nocivas (FANs), sugerindo condutas e cuidados sob tais circunstâncias, particularmente no que diz respeito ao consumo de pescados em geral. Essa oficina foi coordenada pela Profa. Gleyci Moser, do Laboratório de cultivo (LABCULT) da Faculdade de Oceanografia (FAOC/UERJ) e pela Profa. Patrícia Domingos (LabAlgas) do Instituto de Biologia Roberto Alcântara Gomes (IBRAG/UERJ) com a participação de integrantes do PACS (Políticas Alternativas para o Cone Sul) que organizaram o grupo e obtiveram a infraestrutura logística de local. A partir daí surgiu o desejo de desenvolver um projeto que permitisse a discussão sobre um tema central de trabalho dos laboratórios proponentes, nesse caso a temática das FANs, integrado às questões afeitas aos pecadores com as quais tivemos contato naquela ocasião.

\section{Florações de algas nocivas (FANs)}

Florações de algas são eventos cada vez mais frequentes em âmbito mundial e se caracterizam pelo crescimento descontrolado de uma ou poucas espécies, dentre as que compõem a comunidade de microalgas planctônicas, conhecida como fitoplâncton ${ }^{2}$. Sob tais condições as populações de algas em floração são capazes de trazer problemas ecológicos, como por exemplo, limitar a assimilação de oxigênio da água pelos peixes, em função do entupimento de suas brânquias (colmatação) em virtude simplesmente da elevação do número de células na água ${ }^{3}$. Além disso, várias espécies de microalgas produzem toxinas com prejuízos ecológicos, econômicos e danos à saúde pública, como representantes de dinoflagelados, diatomáceas e prymnesiofíceas no ambiente marinho e cianobactérias nas águas continentais ${ }^{4}$.

As consequências dos eventos de FANs para a saúde pública se concretizam principalmente pela via do consumo de peixes e moluscos bivalves. Estes animais podem ser contaminados pelo processo conhecido como bioacumulação, que se caracteriza pelo acúmulo de substâncias persistentes ou pouco móveis ou refratárias à degradação ao longo da cadeia alimentar. Nesses casos os animais, principalmente os carnívoros, acumulam concentrações bem mais elevadas de toxinas, ou quaisquer contaminantes persistentes, que as observadas nas algas.

As toxinas produzidas pelas microalgas são também conhecidas a partir do efeito que causam em seres humanos. Dentre os sintomas que estas podem provocar listam-se os efeitos gastrointestinais (toxinas DSP - Diarrhetic hellfish Poisoning), sintomas gastrointestinais e neurológicos (toxinas PSP Paralitic Shellfish Poisoning e toxinas ASP - Amnesic Shellfish Poisoning), sintomas gastrointestinais e respiratórios (Toxinas NSP - Neurotoxic Shellfish Poisoning). Dentre as microalgas no ambiente marinho, dinoflagelados podem produzir DSP, PSP e NSP enquanto que diatomáceas podem produzir $\mathrm{ASP}^{5}$.

Na Baía de Sepetiba foi reportada a ocorrência de FANs nos anos de $1997^{6}, 1998^{7}$, em $2000^{8}$. Em Mangaratiba, no ano de 2009, embora não tenha sido confirmada a relação direta entre os eventos, registrou-se mortandade de peixes associada à floração de dinoflagelados e diatomáceas potencialmente nocivas. Este fato levou à recomendação para suspensão temporária do consumo de moluscos oriundos da região pela Secretaria Estadual do Ambiente 9 , o que traz reflexos para a economia dos municípios locais, os quais têm nessas atividades uma das fontes de geração de renda e trabalho. Considerando que as FANs representam um cenário capaz de impor drástica 
redução à atividade e ao território de pesca torna-se premente a tomada de ações que tragam a público o conhecimento sobre esses organismos, sendo fundamental a divulgação de causas, riscos e consequências de tais eventos junto às comunidades direta e indiretamente afetadas. Na Baía de Sepetiba, pescadores artesanais, maricultores e os consumidores do pescado fazem parte da comunidade diretamente atingida por tais eventos.

\section{Atividades econômicas e impactos sobre a Baía de Sepetiba}

A situação da Baía de Sepetiba é uma das mais graves, por já haver neste local um histórico de contaminação, desde metais pesados por passivos ambientais, até despejos orgânicos de origem doméstica que causaram alterações irreversíveis para este ecossistema. A este cenário acrescenta-se a implantação de um complexo industrial, abrangendo uma siderúrgica em plena área urbana, a expansão portuária com construção de 5 novos portos ou ampliação de outros pré-existentes, como o Porto de Itaguaí (antigo Porto de Sepetiba) até a previsão de um estaleiro da Marinha para a eventual construção de um submarino atômico. Todas essas atividades são potencialmente poluidoras, inserindo-se no contexto dos megaempreendimentos que o Estado do Rio de Janeiro atraiu com isenções fiscais e o governo federal apoiou com financiamentos bilionários. Estas atividades estão concentradas numa única área com diversas consequências socioambientais, revelando um quadro de injustiça ambiental ao qual estão submetidas as populações daquela área. A Baía de Sepetiba foi considerada zona de sacrifício ambiental ${ }^{10}$, em função da aglomeração de atividades causadoras de impacto ambiental nesta área.

A implantação dos terminais portuários gera as chamadas "zonas de segurança" 11 de $500 \mathrm{~m}$ para cada lado do píer de atracação, que se tornam território da empresa, para garantir que não haja aproximação de outras embarcações. $\mathrm{Na}$ realidade uma significativa área de mar é apropriada, tornando-se um território particular. Os terminais e as áreas de acesso construídas para permitir desembarque e embarque podem alcançar, somadas, alguns quilômetros de extensão, como é o caso da TKCSA (Thyssenkrupp - Companhia Siderúrgica do Atlântico), considerado o maior complexo siderúrgico-portuário da América Latina ${ }^{12}$. Somente a ponte de acesso do Terminal Portuário
Centro Atlântico possui $4 \mathrm{~km}$, enquanto que o terminal da LLX tem uma extensão de $756 \mathrm{~m}$ com uma ponte de acesso de $647 \mathrm{~m}$.

Essa limitação ao uso do território marítimo gera as chamadas zonas de exclusão de pesca, que se traduzem pela restrição da prática da pesca nestes locais. Ao mesmo tempo, a própria implantação das atividades e os processos de dragagem e construção anteriores, foram apontados pelos pescadores como agentes de impacto, como relatado por lideranças locais que atribuíram um evento de mortandade de peixes ao início da dragagem para a construção do porto da TKCSA em outubro de 2006.

Para a construção do Porto Sudeste da LLX Logística, por exemplo, uma grande área com diversas casas, uma escola pública da Rede da Secretaria Municipal de Educação e um posto de atendimento da Secretaria Municipal de Saúde foram retirados em favor da área do empreendimento, restando apenas algumas poucas famílias que permaneceram no local e se recusam a sair. Para facilitar o acesso de mercadorias ao Porto Sudeste está em construção um túnel de $1500 \mathrm{~m}$ na região.

Apesar de ser aclamado como o maior complexo portuário da América Latina e a Siderúrgica do Atlântico ser considerada a mais moderna da América Latina ${ }^{12}$ acidentes resultando nos eventos da chamada "chuva de prata" foram registrados. Tais eventos resultam da liberação de um material particulado que contamina o ar e se deposita sobre a residência de moradores de Santa Cruz e adjacências. Relatório da FIOCRUZ ${ }^{13}$ informa o agravamento da poluição atmosférica após o início da operação do primeiro alto-forno da TKCSA. O mesmo estudo relata que, pouco após o início das operações da siderúrgica, em julho de 2010, os moradores já detectavam a presença do pó prateado, com os consequentes problemas respiratórios, dermatológicos e oftalmológicos. A análise da composição deste particulado mostrou a presença dos elementos Alumínio, Arsênio, Bário, Bromo, Cálcio, Cádmio, Cério, Cloro, Cromo, Cobre, Ferro, Potássio, Lantânio, Magnésio, Manganês, Neodímio, Níquel, Fósforo, Chumbo, Praseodímio, Rubídio, Enxofre, Estrôncio e Zinco.

Segundo a análise do INEA, houve um incremento de mais de $1000 \%$ de Ferro no ar em relação aos teores encontrados na região antes do início da pré-operação da TKCSA. A exposição ambiental a altas concentrações de ferro pode ge- 
rar efeitos nocivos à saúde dentro os quais danos pulmonares e hepáticos, pancreatite, diabetes e anormalidades cardíacas ${ }^{13}$. A exposição de moradores é agravada pela proximidade das residências em relação à área das instalações da siderúrgica com a qual fazem fronteira. A legislação alemã, por exemplo, prevê uma distância mínima de $1500 \mathrm{~m}$ em relação ao empreendimento ${ }^{11}$.

O evento de 2010 foi, segundo denúncia da comunidade local, provocado pelo armazenamento contínuo de ferro gusa em poços ao ar livre da região e apontou para o agravamento de problemas como dermatites, irritação de mucosas e problemas respiratórios diversos ${ }^{13}$. Por esse motivo o Ministério Público Estadual (MPE) realizou denúncia em 02 de dezembro de 2010 contra a TKCSA por crimes ambientais em decorrência da poluição atmosférica em níveis capazes de provocar danos à saúde humana, afetando principalmente as comunidades vizinhas da usina, em Santa Cruz. Os eventos de "chuva de prata" já registrados foram em agosto e dezembro de 2010, em outubro de 2012 e em fevereiro de $2013^{14}$.

Discute-se aqui a questão de Sepetiba, mas toda a questão de degradação de corpos de água costeiros por empreendimentos poluidores e os impactos socioambientais e econômicos representa o foco de uma luta de pescadores artesanais que tem amplitude nacional e mesmo internacional, como pudemos constatar na Rio +20 , que tem recebido pouca atenção da sociedade.

Logo após o término da Rio + 20, a Associação Homens e Mulheres do Mar (AHOMAR) denunciava o assassinato de dois pescadores que lutavam contra os grandes empreendimentos do petróleo na Baía de Guanabara. Seus corpos foram encontrados com as mãos amarradas. A violência contra pescadores tornou-se uma constante em nosso estado. Por conta das sucessivas ameaças e atentados à vida $^{15}$, um líder da AHOMAR, Alexandre Anderson, vive com sua família sob a proteção do Programa de Defensores dos Direitos Humanos.

\section{Projeto sobre FANs numa perspectiva socioambiental}

Nesse contexto, grupos da UERJ, de diferentes institutos e faculdades, juntaram-se em torno da questão: os atuais processos de degradação que se verificam na Baía de Sepetiba. Após a eleição deste ecossistema como tema de trabalho, nosso grupo do Laboratório de Algas (LabAlgas) do IBRAG, associou-se ao Laboratório de Cultivo (Labcult) da FAOC e ao Núcleo de Estudos Interdisciplinar da Baixada Fluminense (NIESBF) Faculdade de Educação da Baixada Fluminense (FEBF) para propor um projeto em maio de 2012 sobre Florações de Algas Nocivas (FANs), intitulado "Conhecendo as FANS", sob coordenação da Profa. Dra. Gleyci Moser (FAOC) no âmbito do Edital FAPERJ $n^{\circ}$ 14/2012 - Apoio a Projetos de Extensão e Pesquisa - EXTPESQ. A proposta de trabalho em Sepetiba incorporou posteriormente uma vertente de trabalho com escolas públicas e pescadores locais, $\mathrm{A}$ incorporação da vertente com escolas públicas permitiu a aproximação com o trabalho do Grupo de Estudos e Pesquisa em Educação Ambiental, Diversidade e Sustentabilidade (GEPEADS) da Universidade Federal Rural do Rio de Janeiro (UFRRJ), por intermédio do Dr. Mauro Guimarães. A articulação com este projeto viabilizou a divulgação de nosso tema de trabalho junto aos professores de 40 escolas públicas da educação fundamental da região. O objetivo é contribuir para que os professores sintam-se encorajados e seguros para desenvolverem projetos escolares que incorporem a temática de FANs e a problemática socioambiental da Baía de Sepetiba. Para isso encontros entre professores e participantes do projeto são realizados. As atividades realizadas para o grupo de professores, até aqui, incluíram uma palestra sobre FANs e apresentação de material lúdico sobre o tema e um trabalho de campo na Baía. O material lúdico é composto de jogos que permitam maior compreensão por parte dos alunos de temáticas como bioacumulação, teia trófica, além de um jogo de simulação de papéis (JSP), confeccionado para o projeto. Neste jogo são criados vários personagens que, a partir de um roteiro, participam de uma discussão geral sobre a questão dos impactos socioambientais da baía. Os personagens são indivíduos ou atores sociais que estejam direta ou indiretamente envolvidos na problemática. Cada estudante assume um personagem e deverá debater o tema, sustentando as ideias de seu personagem. $\mathrm{O}$ trabalho de campo com o grupo de professores foi uma atividade semelhante ao "TOXIC TOUR" de que participamos durante a Rio +20 , para o qual convidamos o pescador Isac Alves, uma das lideranças locais, que conduziu um relato sobre as percepções e perspectivas dos pescadores da região, durante a visita na Baía de Se- 
petiba. Nesse trabalho de campo, foi possível uma observação próxima dos terminais portuários e do carregamento para um navio atracado, sem o devido cuidado para evitar a queda acidental de minério de ferro no corpo d'água. Foi ainda realizada coletas com rede de amostras do fitoplâncton para a observação ao microscópio pelos professores. Toda a visitação foi documentada com fotos e vídeos.

$\mathrm{O}$ projeto se desenvolve com o monitoramento da comunidade fitoplanctônica da Baía de Sepetiba para a identificação de possíveis eventos de FANs, com frequência mensal, desde fevereiro de 2013, permitindo o contato regular com os pescadores e atualização constante de sua percepção sobre seu território de pesca, suas lutas por compensações das perdas sofridas e suas perspectivas por vias alternativas de sustento.

Nas amostras tem sido observada em quase todos os meses a presença de Pseudo-nitzschia sp., gênero de diatomácea que possui algumas espécies associadas à produção de ácido domóico, um aminoácido tóxico, que causa envenenamento amnésico por consumo de mariscos (ASP). Os sintomas desta intoxicação incluem náuseas, vômitos, diarréia e cólicas abdominais e, em casos mais graves, observam-se diminuição do reflexo, dores fortes, tontura, alucinações, confusão mental, e perda da memória de curto prazo. Podem ocorrer ataques ou acessos ${ }^{16 \text { e } 2}$. O simples registro de ocorrência, entretanto, não significa uma exposição à contaminação, uma vez que as biomassas, até então registradas, podem ser consideradas baixas e médias, considerando os valores de clorofila a obtidos. As análises do mês de julho registraram ainda a presença de Dinophysis sp., gênero frequentemente associado à intoxicação diarréica por consumo de moluscos (DSP). Serão realizadas análises para testar a toxicidade desta amostra, mas os riscos tornam-se reais apenas a partir de um número significativo de células nas populações naturais.

Participam deste projeto ainda estagiários que se envolvem com as atividades de extensão através das coletas, frequentam o curso realizado pela UFRRJ e contribuem para a construção de material didático (jogo). Este jogo será mais um material específico para o projeto e será elaborado a partir das entrevistas mensais realizadas com os pescadores. A partir da referência cartográfica da baía de Sepetiba pretende-se mapear o território de pesca, como concebido pelos pescadores, incluindo referências de tempo e espaço de suas práticas pesqueiras (época do ano de maior rendimento pesqueiro, espécies e suas localizações, alterações ao longo dos anos, metodologia de pesca para cada espécie). Dessa forma, pretende-se através da comunicação cartográfica, incorporar os relatos dos pescadores sobre sua realidade local. Neste mapeamento serão incluídos ainda os resultados do monitoramento do fitoplâncton, percebidos como eventos que reduzem o território pesqueiro.

\section{Conclusão}

Espera-se que este projeto possa contribuir para que as comunidades pesqueira e litorânea local estejam informadas sobre os problemas de saúde pública relacionados ao consumo de pescado e frutos do mar durante eventos de FANs e que as comunidades escolares (professores, alunos e familiares) do entorno da região tenham acesso ao maior conhecimento sobre causas e consequências das FANs no ambiente de estudo, bem como as alternativas para redução dos riscos para a saúde.

A universidade pode abrir espaço para a discussão dessa questão por professores e estudantes, colaborando para a construção de uma atitude mais atenta à realidade de seu tempo e localidade e para a elaboração de uma visão crítica que permita mesmo a articulação para produzir intervenções sobre essa realidade.

Como um dos produtos deste projeto pretende-se concluir a confecção de uma cartografia socioambiental a partir da percepção de pescadores acerca de seu território pesqueiro na baía e os impactos impostos pelas atividades econômicas em expansão na área. A esta percepção pretende-se incorporar, também sob a forma de comunicação cartográfica, os resultados do monitoramento do ecossistema, incluindo as eventuais florações ocorridas durante a duração deste projeto. $\mathrm{O}$ resultado será disponibilizado como material didático específico do projeto para as escolas participantes.

\section{Agradecimentos}

A SR3/UERJ pelo apoio para o desenvolvimento deste projeto através da concessão de bolsa. A FAPERJ pelos recursos financeiros, concedidos a Profa. Dra. Gleyci Moser, através do edital EXT- 
PESQ 2012 (proc. FAPERJ E26/111.525/2012), à Associação de Pescadores Cercadeiros de Pedra de Guaratiba, que colaboram para a realização este projeto, ao Grupo de Estudos e Pesquisa em Educação Ambiental, Diversidade e Sustentabilidade (GEPEADS) da Universidade Federal Rural do Rio de Janeiro (UFRRJ), através do Prof. Dr. Mauro Guimarães e Profa. Dra Cristiane Cardoso que se dedicaram a promover a integração entre os projetos em ações conjuntas, potencializando o alcance das duas proposições.

\section{Referências}

1. Disponível em (http://global.org.br/arquivo/noticias/ edicao-2012-do-globale-estreia-com-filmes-do-toxic-tour-veja-as-fotos/).

2. HALLEGRAEFF, Gustaaf. Ocean climate change, phytoplankton community responses, and harmful algal blooms: a formidable predictive challenge. Journal of Phycology, v. 46, p. $220-235,2010$.

ANDERSON, Donald. The ecology and oceanography of harmful algal bloom: multidisciplinary approaches to research and management. Anton Bruun Memorial Lectures. Intergovernamental Oceanographic Commission. UNESCO, Paris, 2005. 38p

4. CASTRO, Natália Oliveira e MOSER, Gleyci de Oliveira. Florações de algas nocivas e seus efeitos ambientais. Oecologia Australis, v.16, n. 2, p. 235-264, 2012.

5. HALLEGRAEFF, Gustaav, ANDERSON, Donald, CEMBELLA, Allan e ENEROLDSEN, Henrik. Manual on harmful marine microalgae, Unesco, Paris, 2003.

6. ODEBRECHT, Clarice, HUSZAR, Vera-Lúcia, MENEZES, Mariângela, YUNES, João, PROENÇA, Luiz-Antonio, VILLAC, Maria-Célia e TENEMBAUM, Denise. Floraciones de microalgas nocivas en Brasil: estado del arte y projectos en curso. In Floraciones algales nocivas en El Cono Sur Americano, Sar., In: E.A., Ferrario, M.E. \& Reguera, B. (Org.). 2002. v. 1, p. 1-307. Unesco-IEO, Madrid, 2002

7. VILLAC, Maria-Célia, MELO, S.; MENEZES, Mariângela e TENEMBAUM, Denise. Pseudo-nitzschia brasiliana (Bacillariophyceae), an opportunistic diatom on the coast of the state of Rio de Janeiro, Brazil. Atlântica, Rio Grande, v. 27, n. 2, p. 139-145, 2005.

8. MAGALHÃES, Valéria, MARINHO, Marcelo, DOMINGOS, Patrícia, OLIVEIRA, Ana-Cláudia COSTA, Simone, AZEVEDO, Luiz-Otávio, AZEVEDO, Sandra-Maria. Microcystins (cyanobacteria hepatotoxins) bioaccumulation in fish and crustaceans from Sepetiba Bay (Brasil, RJ). Toxicon, v. 42, p. 289-295, 2003.

9. OGLOBO. Moluscos contaminados. Edição de 01 de junho de 2009, Matutina, Rio, p. 11

10. ACSELRAD, Henri. As práticas espaciais e o campo dos conflitos ambientais. In: ACSELRAD, Henri (org.). Conflitos Ambientais no Brasil. Rio de Janeiro: Relume Dumará: Fundação Heinrich Böll, 2004. p.13-35.
11. NORMAM-07. Normas da Autoridade Marítima para Atividades de Inspeção Naval. Marinha do Brasil. Diretoria de Portos e Costas. 32 p., 2005.

12. PACS- Instituto Políticas Alternativas para o Cone Sul. Companhia Siderúrgica do Atlântico- TKCSA: Impactos e irregularidades na Zona Oeste do Rio de Janeiro. $2^{\mathrm{a}}$ ed. Rio de Janeiro. 2009. 84p.

13. PORTO, Marcelo Firpo, MENEZES, Marco-Antonio, DIAS, Alexandre e BÚRIGO, André. Avaliação dos impactos socioambientais e de saúde em Santa Cruz decorrentes da instalação e operação da empresa TKCSA. Relatório ENSP/ Fundação Oswaldo Cruz. 2011. 66p. Disponível em www.epsjv.fiocruz.br/upload/d/Relatorio_TKCSA.pdf

14. PACS- Instituto Políticas Alternativas para o Cone Sul. Até quando TKCSA terá licença para produzir "chuva de prata" em Santa Cruz? Informativo de 26 de fevereiro de 2013. Disponível em: http://www.pacs.org.br/2013/02/26/ ate-quando-a-tkcsa-tera-licenca-para-produzir-chuva-de-prata-em-santa-cruz/

15. Informativo Passa-Palavra de 29 de junho de 2012. Ato repudia assassinatos de pescadores da Baía de Guanabara. Disponível em (http://passapalavra.info/2012/06/61200 e http://global.org.br/tag/ahomar/).

16. Página Algas Nocivas IFSC - Itajaí. Síndromes - Envenenamento amnésico por consumo de mariscos - ASP. Disponível em (http://algasnocivas.pro.br/ASP.html).

\section{Abstract}

This report describes the initial steps of a community Project supported by IBRAG, FAOC, NIES$B E F / U E R J$ and GEPEADS/UFRRJ about the risks of harmful algal bloom (HABs) and current social impacts in the Sepetiba Bay. The main objectives are: (I) contributing to discussion and awareness of the problem by professors and students of 40 state schools situated around the bay; (II) monitoring the HABs occurrence and (III) mapping the fishermen perceptions of their fishing territory. The Sepetiba Bay region has received, in the past few years, great industrial projects and new port terminals. Creating the fishing exclusion zones. Also, past HABs records in the bay along with the threat of brand new blooms are proven to be factors which reduce the fishing area, not to mention possible risks to the environment and human beings. It is essential to spread the causes and effects of HABs in order to contribute to the collective construction of attitudes that minimize their risks for public health, Thus, samples of water from the bay have been taken monthly since February 2013 in order to monitor the HABs. Interviews with the fishers, together with the analysis of water, will subsidize the production of material for the schools.

Keywords: Sepetiba Bay; Harmful Algal Bloom; Fishing Territory. 